\title{
Relative Potency in Acute and Chronic Suppressive Effects of Prednisolone and Betamethasone on the Hypothalamic- Pituitary-Adrenal Axis in Man
}

\author{
Yasuhiko MORIMOTO, TATSUo OISHI, Nobuo HANASAKI, \\ AKiniko MIYATAKE, KeIzo NOMA AND Yuichi YAMAMURA \\ The Third Department of Internal Medicine, Osaka University \\ School of Medicine, Fukushima-ku, Osaka 553, Japan
}

\begin{abstract}
The relative potency in the hypothalamic-pituitary-adrenal (HPA) suppression of both predmisolone and betamethasone was examined in an acute study with normal volunteers and in a chronic study with glucocorticoid-treated patients. Circadian rhythm of plasma cortisol was studied after a single dose administration of 5 to $30 \mathrm{mg}$ prednisolone or 0.5 to $3.0 \mathrm{mg}$ betamethasone at $08: 00 \mathrm{hr}$. Morning-rise of plasma cortisol occurred on the morning after the administration of $30 \mathrm{mg}$ or less prednisolone but no morning rise was noted after the administration of $1.0 \mathrm{mg}$ or more betamethasone. Plasma ACTH was slightly elevated on the morning after $30 \mathrm{mg}$ prednisolone administration but showed low levels throughout the night after $3.0 \mathrm{mg}$ betamethasone administration. Plasma cortisol responsiveness to ACTH was examined in patients before and during therapy with either prednisolone or betamethasone. The basal cortisol level was not suppressed and the responsiveness to ACTH remained nearly normal during long-term $5 \mathrm{mg}$ prednisolone therapy, but these were completely suppressed during long-term $0.5 \mathrm{mg}$ betamethasone therapy. The responsiveness to ACTH was nearly normal in patients receiving alternate-day therapy with prednisolone in such large doses as 50 or $60 \mathrm{mg}$ every other day, but was completely suppressed in patients receiving $1.0 \mathrm{mg}$ betamethasone every other day. The relative potency of betamethasone in acute and chronic suppressive effects on the HPA system seems to be much stronger than that of prednisolone in equivalent doses with comparable anti-inflammatory effects. It is also suggested that the alternate-day therapy with such long-acting steroids as betamethasone are useless in preventing HPA suppression.
\end{abstract}

Both prednisolone and betamethasone are the glucocorticoids used most frequently in Japan at present. They are often simply exchanged for each other in the dose ratio of $10: 1$, because a single tablet contains either $5 \mathrm{mg}$ of prendnisolone or $0.5 \mathrm{mg}$ of betamethasone as an equivalent dose. This equivalency, however, has been decided on the basis of very early reports (Silber,

Received May 2, 1980.

Author's address: Yasuhiko Morimoto, M. D. The Third Department of Internal Medicine, Osaka University Hospital, Fukushima-ku, Osaka 553, Japan.
1959; Tolksdorf, 1959; Boland, 1961 ; Roberts, 1962).

Later, Thorn and his colleagues (Harter, 1966; Thorn and Lauler, 1972) classified glucocorticoid derivatives into short-acting, intermediate-acting and long-acting on the basis of their duration of suppressive effect on human hypothalamic-pituitary-adrenal (HPA) function. In their studies, prednisolone has been classified as short-acting and betamethasone as long-acting. Nevertheless, few studies have been made on the difference between their suppressive effects on HPA function in the practical field. 
This study was undertaken to clarify the difference between the suppressive effects of these two steroids on the HPA function. For this purpose, acute effect was examined through the suppression of the circadian rhythm of plasma cortisol or ACTH in normal volunteers, and the chronic effect was also studid through the adrenocortical responsiveness to ACTH in patients receiving a long-term administration of these steroids in various doses or under various regimens.

\section{Materials and Methods}

\section{Examination for acute effect}

Six healthy male volunteers (\#1-6) aged 28 to 42 years were studied. All subjects were members of the medical or paramedical staff of Osaka University Hospital. They were all physically normal, having no history of endocrine, renal, hepatic or cardiovascular disease and without any self-medications. All experiments were performed within their daily activity patterns with usual sleep. All blood samples were drawn by venipuncture even during the sleep period.

In Subject \#1, hrs blocd samples were drawn every $2-4 \mathrm{hr}$ through $28 \mathrm{hrs}$ from $08: 00 \mathrm{hr}$. Similar blood samplings were repeated 3 times at intervals of one week. No drug was given in the first experiment. In the 2nd experiment $10 \mathrm{mg}$ of prednisolone and in the $3 \mathrm{rd}$ experiment $1.0 \mathrm{mg}$ of betamethasone were administered at $08: 00 \mathrm{hr}$ immediately after the first blood sampling. Both prednisolone (Predonine) and betamethasone (Rinderon) were purchased from Shicnogi Pharmaceutical Co. Ltd., Osaka, Japan.

In 3 volunteers (Subjects $\# 1-3$ ), blood was sampled successively throughout $48 \mathrm{hrs}$ at $12 \mathrm{hr}$-intervals. The blood samplings were repeated nine times in each subject in the same manner at intervals of about 2 weeks. In the first study no drug was given. Then in the remaining 8 studies, $5,10,20$ or $30 \mathrm{mg}$ of prednisolone or $0.5,1.0,2.0$ or $3.0 \mathrm{mg}$ of betamethasone was administered in random order in a single dose at $08: 00 \mathrm{hr}$ immediately after the first blood was sampled.

In 3 other volunteers (Subjects \#4-6), blood was sampled every $2-4 \mathrm{hr}$ throughout night after the administration of $30 \mathrm{mg}$ prednisolone at $08: 00 \mathrm{hr}$ or after the administration of $3.0 \mathrm{mg}$ betamethasone at $08: 00 \mathrm{hr} 2$ weeks later.

Plasma was separated immediately and stored at $-20^{\circ} \mathrm{C}$ until assay for cortisol or ACTH.

\section{Examination for chronic effect}

$250 \mu \mathrm{g}$ of synthetic $\alpha^{1-24} \mathrm{ACTH}$ (Cortrosyn, Daiichi Pharmaceutical Co. Ltd., Tokyo, Japan) was injected intramuscularly between $08: 00$ and $10: 00 \mathrm{hr}$ into patients before and during the glucocorticoid therapy with various doses of either prednisolone or betamethasone for more than 1 month. The illnesses of these patients included bronchial asthma, rheumatoid arthritis, systemic lupus erythematosus, sarcoidosis, nephrotic syndrome, idiopathic thrombocytopenic purpura, aplastic anemia, ulcerative colitis and terminal ileitis. The total number of patients was 110 cases (52 males and 58 females, aged 14$73 \mathrm{y})$.

In the daily regimen, prednisolone was given in daily divided doses to all patients who received more than $15 \mathrm{mg}$ and in 11 patients who received $10 \mathrm{mg}$, and in a single dose in the morning in 4 patients who received $10 \mathrm{mg}$ and in all patients receiving $5 \mathrm{mg}$. Betamethasone was given in daily divided doses to all patients who received more than $1.0 \mathrm{mg}$ and in a single dose to all patients receiving $0.75 \mathrm{mg}$ or less. In the alternate-day regimen, the steroids were administered in a single dose in the morning of every second day, from the beginning to the end of the therapy.

In either the daily regimen or alternateday regimen, the steroids were administered initially in large doses and thereafter tapered gradually. Therefore, patients who received larger doses of the steroids corresponded to those who had taken them for a shorter period and the patients who received smaller doses corresponded to those who had received a long-term therapy in general. Some patients were studied more than twice using different steroid dosages.

ACTH was injected between $08: 00-10: 00 \mathrm{hr}$, at least $12 \mathrm{hr}$ after the last steroid administration in the daily regimen and $48 \mathrm{hr}$ after the last steroid administration in the alternate-day regimen. Blood sampling was performed immediately before the ACTH injection and at 30 and $60 \mathrm{~min}$ after the injection. All blood sampling was completed before taking any medication on the same morning.

\section{Measurement of cortisol and ACTH}

Plasma cortisol concentrations were measured by the competitive protein binding assay of Murphy (1967). When prednisolone was administered, plasma cortisol was not determined for at least $6 \mathrm{hr}$ after the administration since it is known that prednisolone binds strongly to transccrtin and interferes with the measurement (Murphy, 1969; Ballard et al., 1975) and that the half-life of prednisolone is known to be about $200 \mathrm{~min}$ (Peterson, 1959).

The plasma cortisol concentrations in 23 normal subjects studied in our laboratory were $12.8 \pm 3.8 \mu \mathrm{g} / \mathrm{d} l$ at $08: 00 \mathrm{hr}$ and $8.4 \pm 4.0 \mu \mathrm{g} / \mathrm{d} l$ at $12: 00 \mathrm{hr}$ (mean \pm $\mathrm{SD})$. The response of plasma cortisol to an intra- 

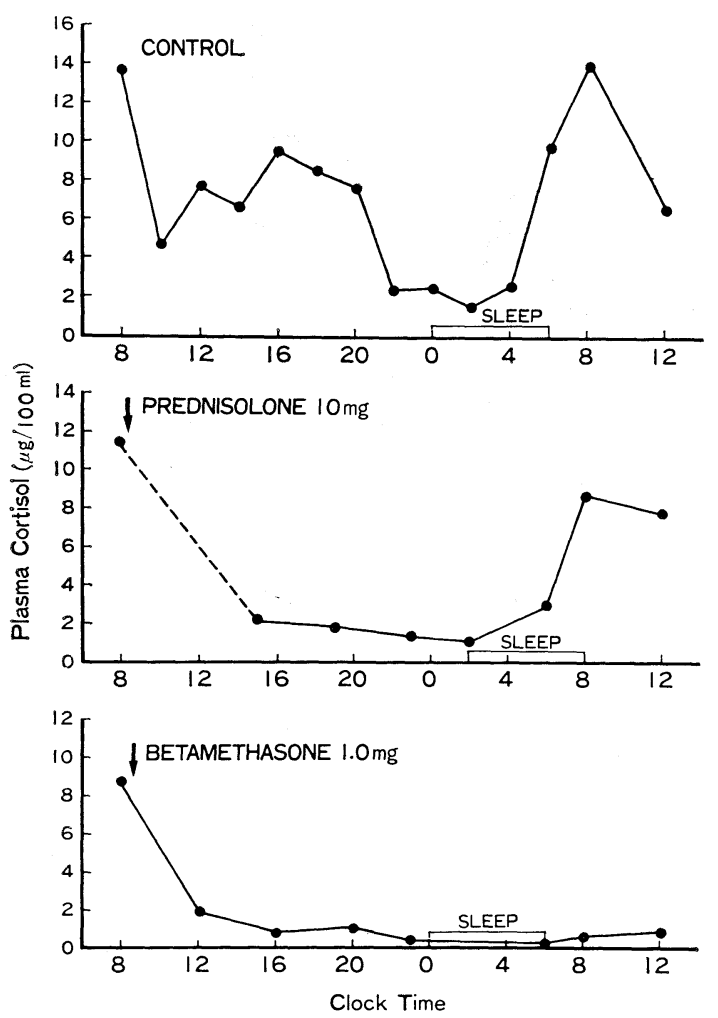

Fig. 1. The circadian rhythm of plasma cortisol levels in a normal subject on the control day, on the day when a single dose of $10 \mathrm{mg}$ prednisolone was given at $08: 00 \mathrm{hr}$ and on the day when a single dose of $1.0 \mathrm{mg}$ betamethasone was given at $08: 00 \mathrm{hr}$.

muscular injection of $250 \mu \mathrm{g} \alpha^{1-24} \mathrm{ACTH}$ in 22 normal subjects in our laboratory is shown in Table 1 and 2.

The plasma ACTH concentration was measured by RIA (Berson and Yalow, 1968; Besser et al., 1971) using kits purchased from Radiochemical Centre, England. The plasma ACTH levels measured by this assay system in our laboratory were $49.3 \pm 21.3$ $\mathrm{pg} / \mathrm{ml}$ at $08: 00 \mathrm{hr}$ in 20 normal subjects and $33.6 \pm$ $15.6 \mathrm{pg} / \mathrm{ml}$ at $20: 00 \mathrm{hr}$ in 7 normal subjects (mean \pm SD).

The statistical difference between the mean plasma cortisol levels was assessed by Student's $t$-test.

\section{Results}

1. Acute effect on the circadian adrenocortical rhythm in normal subjects

The circadian rhythms of plasma cor-

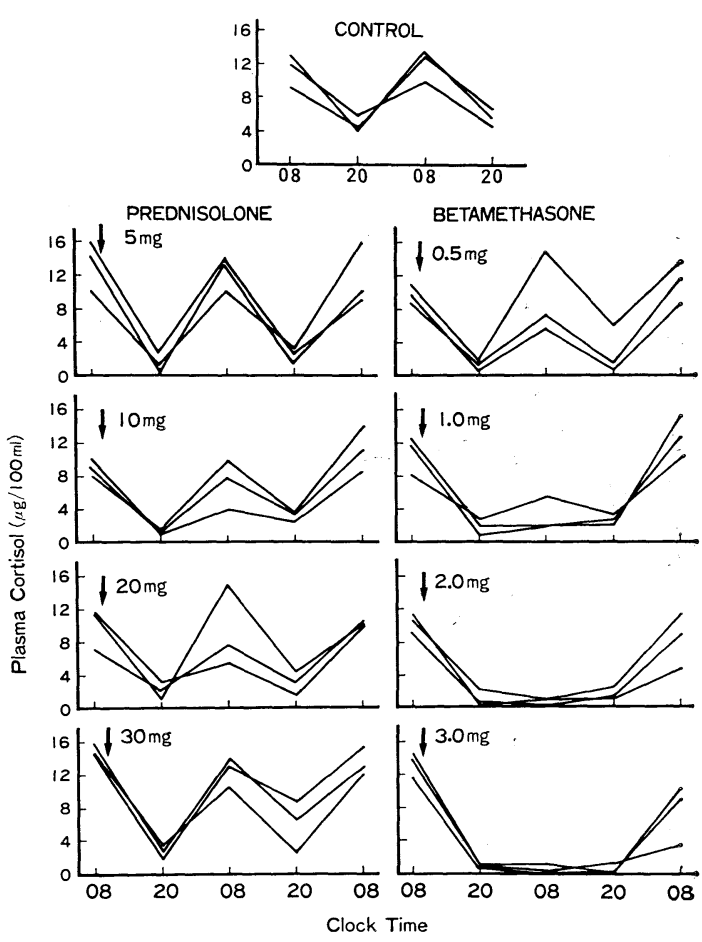

Fig. 2. The individual variations in plasma cortisol in three normal subjects after a single administration of various doses of either prednisolone or betamethasone at $08: 00 \mathrm{hr}$.

tisol in 3 experiments with Subject $\# 1$ are shown in Fig. 1. In the first experiment when no drug was given, the circadian rhythm showed a normal pattern with the peak at $08: 00 \mathrm{hr}$ and the nadir at $02: 00$ $\mathrm{hr}$. When a single dose of $10 \mathrm{mg}$ prednisolone was administered at $08: 00 \mathrm{hr}$ in the second experiment, plasma cortisol showed low levels throughout the night but rose to a near control level at $08: 00 \mathrm{hr}$ on the next morning. However, when a single dose of $1.0 \mathrm{mg}$ betamethasone was given in the third experiment, plasma cortisol showed consistent low levels throughout $28 \mathrm{hrs}$ and no morning rise occurred with this treatment.

The individual variations in plasma 

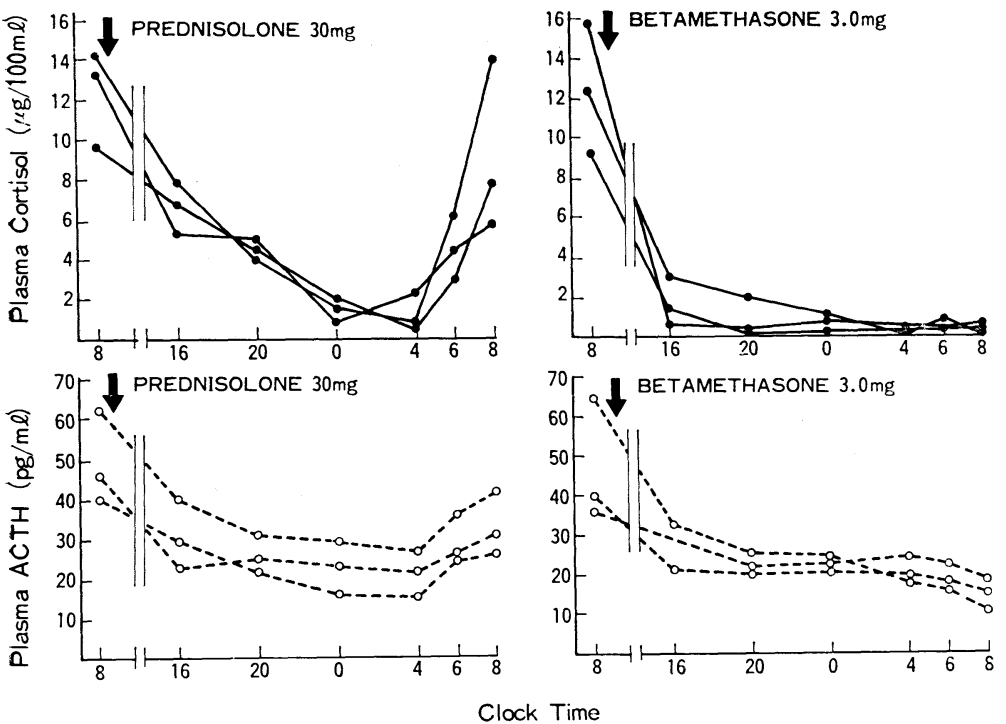

Fig. 3. The circadian variation in plasma cortisol (upper figures) and ACTH (lower figures) in three normal subjects after a single administration of either $30 \mathrm{mg}$ prednisolone (left side) or $3.0 \mathrm{mg}$ betamethasone (right side) at $08: 00 \mathrm{hr}$. cortisol in 3 normal subjects (\#1-3) after a single administration of various doses of either prednisolone or betamethasone are shown in Fig. 2. Even when such a large dose as $30 \mathrm{mg}$ of prednisolone was administered, the values at $08: 00 \mathrm{hr}$ on the following day were elevated to nearly normal levels. On the other hand, when a single dose of $1.0 \mathrm{mg}$ or more of betamethasone was administered, no morning rise was noted at $08: 00 \mathrm{hr}$ on the second day.

The circadian variations in plasma cortisol and ACTH in 3 normal subjects (\#4-6) after a single dose administration of either $30 \mathrm{mg}$ prednisolone or $3.0 \mathrm{mg}$ betamethasone at $08: 00 \mathrm{hr}$ are shown in Fig. 3. Plasma cortisol levels in each subject showed an obvious morning rise after the administration of $30 \mathrm{mg}$ prednisolone. Plasma ACTH levels also tended to rise after $04: 00 \mathrm{hr}$. On the other hand, after the administration of $3.0 \mathrm{mg}$ betamethasone at $08: 00 \mathrm{hr}$, plasma cortisol levels were extremely low throughout the night and showed no morning rise and plasma ACTH levels tended to decline toward the following morning.
2. Chronic effect on the adrenocortical responsiveness to ACTH in patients receiving glucocorticoid therapy

Plasma cortisol levels in patients before glucocorticoid therapy were significantly lower than in normal subjects both before $(\mathrm{p}<0.01)$ and $60 \mathrm{~min}$ after $(\mathrm{p}<0.05)$ ACTH injection (Table 1). Therefore, all plasma cortisol values in patients receiving glucocorticoids were compared to the values in the untreated patients instead of the values in normal subjects.

The mean basal cortisol levels in patients receiving $10 \mathrm{mg}$ or more of prednisolone daily were significantly lower than those in the untreated patients, but the value in patients receiving $5 \mathrm{mg}$ once every morning did not differ significantly $(p>0.1)$. The cortisol level measured $60 \mathrm{~min}$ after ACTH was suppressed to less than $5.0 \mu \mathrm{g} / \mathrm{d} l$ in patients who received $15 \mathrm{mg}$ or more of prednisolone daily. The patients receiving $10 \mathrm{mg}$ prednisolone in daily divided doses also showed a low basal cortisol level and poor responsiveness to ACTH, but those who received $10 \mathrm{mg}$ in a single dose every morning showed a higher basal level and 
Table 1. The response of plasma cortisol to the injection of $250 \mu \mathrm{g}$ synthetic $\alpha^{1-24} \mathrm{ACTH}$ in patients receiving daily administration of prednisolone or betamethasone

\begin{tabular}{|c|c|c|c|c|c|}
\hline \multirow[b]{2}{*}{ Treatment } & \multirow{2}{*}{$\begin{array}{c}\text { Number of } \\
\text { cases }\end{array}$} & \multicolumn{4}{|c|}{ Plasma cortisol concentration $(\mu \mathrm{g} / \mathrm{d} l)$} \\
\hline & & Before ACTH & $30 \mathrm{~min}$ & $60 \mathrm{~min}$ & Increment* \\
\hline Normal subjects & 12 & $9.3 \pm 2.5$ & $17.2 \pm 3.2$ & $21.5 \pm 4.8$ & $12.5 \pm 4.8$ \\
\hline Untreated patients & 26 & $6.5 \pm 2.6$ & $15.3 \pm 3.7$ & $18.4 \pm 3.4$ & $12.0 \pm 2.9$ \\
\hline \multicolumn{6}{|l|}{ Prednisolone } \\
\hline $30 \mathrm{mg} /$ day $\dagger$ & 3 & $2.1 \pm 1.9$ & $2.6 \pm 2.2$ & $3.2 \pm 2.0$ & $1.2 \pm 0.2$ \\
\hline 20 & 5 & $0.6 \pm 1.3$ & $2.5 \pm 1.8$ & $4.0 \pm 2.4$ & $3.5 \pm 2.7$ \\
\hline 15 & 10 & $1.3 \pm 1.0$ & $3.4 \pm 2.2$ & $4.3 \pm 2.9$ & $3.0 \pm 1.9$ \\
\hline b.i.d. & 11 & $1.9 \pm 1.4$ & $3.0 \pm 2.0$ & $4.4 \pm 3.5$ & $2.6 \pm 2.8$ \\
\hline \multirow{2}{*}{$10\left\{\begin{array}{l}\text { single dose in the } \\
\text { morning }\end{array}\right.$} & 4 & $3.4 \pm 1.2$ & $7.8 \pm 3.6$ & $8.8 \pm 4.7$ & $5.3 \pm 3.6$ \\
\hline & 9 & $5.5 \pm 2.2 \S$ & $9.0 \pm 2.5$ & $12.0 \pm 3.2$ & $6.5 \pm 2.5$ \\
\hline \multicolumn{6}{|l|}{ Betamethasone } \\
\hline $2.0 \mathrm{mg} /$ day ${ }^{\dagger}$ & 3 & $0.6 \pm 0.5$ & $1.1 \pm 0.4$ & $1.4 \pm 0.9$ & $0.9 \pm 0.5$ \\
\hline 1.5 & 3 & $0.9 \pm 0.5$ & $1.3 \pm 0.7$ & $1.7 \pm 0.5$ & $0.8 \pm 0.2$ \\
\hline 1.0 & 4 & $1.1 \pm 0.7$ & $2.4 \pm 1.7$ & $2.0 \pm 1.3$ & $1.4 \pm 1.1$ \\
\hline 0.75 & 3 & $1.8 \pm 1.0$ & $3.8 \pm 2.0$ & $3.3 \pm 1.5$ & $2.1 \pm 1.6$ \\
\hline 0.5 & 12 & $1.6 \pm 1.3$ & $3.4 \pm 2.0$ & $5.2 \pm 2.7$ & $3.8 \pm 2.6$ \\
\hline
\end{tabular}

Values are expressed as the mean $\pm \mathrm{SD}$.

* The increment from the basal value to the maximum response either $30 \mathrm{~min}$ or $60 \mathrm{~min}$ after ACTH stimulation.

$\S$ No significant difference ( $\mathrm{p}>0.1$ ) vs. untreated patients.

$\uparrow$ The data at smaller doses generally indicate the results after long-term treatment, because the steroid doses were gradually tapered.

an improved response to ACTH. The patients who received $5 \mathrm{mg}$ of prednisolone once every morning showed markedly improved responsiveness to $\mathrm{ACTH}$, but the cortisol level measured $60 \mathrm{~min}$ after ACTH or the increment was still significantly $(\mathrm{p}<$ 0.001 , either) lower than the values in the untreated patients (Table 1). The mean cortisol levels in patients receiving $0.5 \mathrm{mg}$ or more of betamethasone daily were consistently below $2.0 \mu \mathrm{g} / \mathrm{d} l$, and the responsiveness to ACTH was markedly suppressed with increments less than $4.0 \mu \mathrm{g} / \mathrm{d} l$ (Table 1).

When the cortisol levels of patients receiving $5 \mathrm{mg}$ prednisolone are compared. to those receiving $0.5 \mathrm{mg}$ betamethasone in a so-called equivalent dosage, it is found. that all cortisol values $(0,30$ and $60 \mathrm{~min}$ after ACTH, $\mathrm{p}<0.001$, each) and the increment $(p<0.05)$ are significantly lower in the latter group. The individual responses to ACTH in patients receiving $5 \mathrm{mg}$ prednisolone are located near the level of the untreated patients, but those in patients: who received $0.5 \mathrm{mg}$ betamethasone are located far below (Fig. 4).

Table 2 shows the plasma cortisol responsiveness to ACTH in patients treated. with the alternate-day regimen. Compared. to the results in the daily regimen with prednisolone (Table 1), both the basal level and response to ACTH showed striking improvement even when such large doses as. 60 or $50 \mathrm{mg}$ were administered every other day. Most of the basal cortisol levels and the increment after ACTH injection obtained from the patients receiving $30 \mathrm{mg}$ or less of prednisolone every other day did not significantly $(p>0.05)$ differ from the values in. the untreated patients (Table 2). However, both cortisol levels and the response to $\mathrm{ACTH}$ in 5 patients receiving $1.0 \mathrm{mg}$ betamethasone every other day were markedly suppressed and they were comparable to the results in patients receiving daily 0.5 . mg betamethasone, as shown in Table 1. 


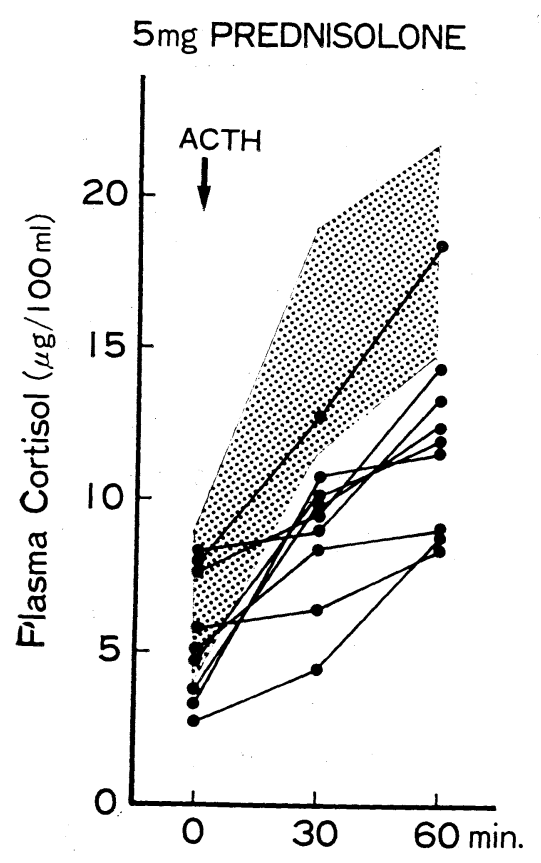

\section{$0.5 \mathrm{mg}$ BETAMETHASONE}

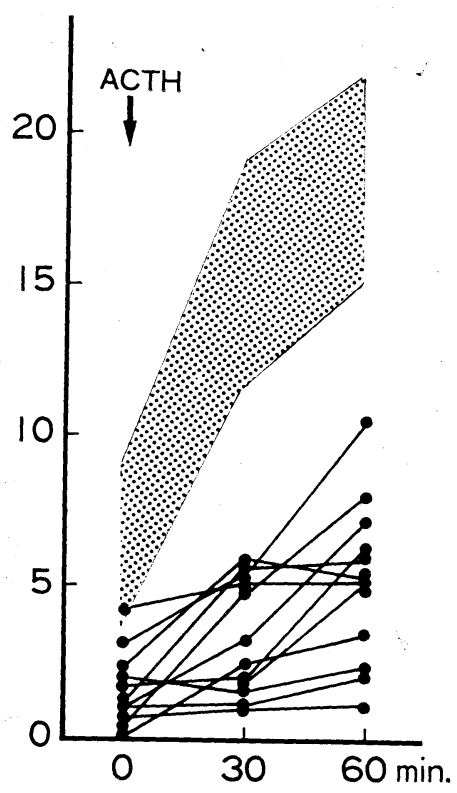

Fig. 4. The individual responses of plasma cortisol to $250 \mu \mathrm{g}$ of $\alpha^{1-24} \mathrm{ACTH}$ in patients receiving longterm treatments with either $5 \mathrm{mg}$ prednisolone or $0.5 \mathrm{mg}$ betamethasone. Shaded areas indicate the mean $( \pm \mathrm{SD})$ response in the untreated patients.

\section{Discussion}

The fact that so-called short-acting steroids and long-acting steroids have almost comparable half-lives in plasma (Melby, 1974; Ballard et al., 1975) suggests that the duration of biological actions of glucocorticoids is not determined by its presence in the circulation but may be determined by such factors as its low affinity for transcortin, relative slow disappearance from plasma and/or the duration of action within target cells (Ballard et al., 1975; Axelrod, 1976; Meikle and Tyler, 1977). In particular, tne difference in the duration of the HPA suppression seems to be accounted for by the difference in the mode of action within the binding site of the hypothalamus or the pituitary gland.

There have been many reports on the effect of dexamethasone on the HPA suppression (Hender, 1967 ; Easton et al., 1971; Ballard et al., 1975; Meikle and Tyler,
1977), but very few reports (Harter, 1966) are available on the effect of betamethasone, another long-acting steroid which is one of the most popular glucocorticoids in Japan at present. Thus, it seems necessary to assess its effect on the HPA suppression exactly.

As it has been well established that the circadian cortisol rhythm is least affected when a single dose of glucocorticoids is administered in the morning (Nichols et al., 1965; Grant et al., 1965), the acute effect on the HPA function was studied by means of a single administration at $08: 00 \mathrm{hr}$ in the present study. The present findings based on the changes in the circadian rhythm of plasma cortisol or ACTH indicate that the acute suppressive effect of a single administration of prednisolone on the HPA system is mild and continues no longer than $24 \mathrm{hrs}$, even when doses as large as $30 \mathrm{mg}$ are administered. On the contrary, the effect of betamethasone given in the same manner seems to be much 
Table 2. The response of plasma cortisol to the injection of $250 \mu \mathrm{g}$ synthetic $\alpha^{1-24} \mathrm{ACTH}$ in patients receiving alternate-day therapy with prednisolone or betamethasone

\begin{tabular}{|c|c|c|c|c|c|}
\hline \multirow{2}{*}{ Treatment } & \multirow{2}{*}{$\begin{array}{c}\text { Number of } \\
\text { cases }\end{array}$} & \multicolumn{4}{|c|}{ Plasma cortisol concentration $(\mu \mathrm{g} / \mathrm{d} l)$} \\
\hline & & Before ACTH & $30 \mathrm{~min}$ & $60 \mathrm{~min}$ & Increment* \\
\hline Normal subjects & 12 & $9.3 \pm 2.5$ & $17.2 \pm 3.2$ & $21.5 \pm 4.8$ & $12.5 \pm 4.8$ \\
\hline Untreated patients & 26 & $6.5 \pm 2.6$ & $15.3 \pm 3.7$ & $18.4 \pm 3.4$ & $12.0 \pm 2.9$ \\
\hline \multicolumn{6}{|l|}{ Prednisolone } \\
\hline $60 \mathrm{mg} /$ every other day $\dagger$ & 8 & $4.0 \pm 2.0$ & $9.7 \pm 2.4$ & $11.5 \pm 3.0$ & $9.7 \pm 3.0$ \\
\hline 50 & 6 & $3.8 \pm 2.8$ & $9.1 \pm 3.3$ & $11.0 \pm 2.4$ & $7.3 \pm 1.9$ \\
\hline $40-35$ & 12 & $4.5 \pm 1.9$ & $9.8 \pm 2.9$ & $13.1 \pm 3.6$ & $8.6 \pm 3.6$ \\
\hline $30-25$ & 13 & $4.7 \pm 2.0 \S$ & $11.5 \pm 3.6$ & $14.7 \pm 4.5$ & $10.1 \pm 4.1 \S$ \\
\hline $20-15$ & 13 & $4.2 \pm 1.9$ & $11.4 \pm 3.6$ & $14.7 \pm 3.5$ & $10.5 \pm 3.4 \S$ \\
\hline 10 & 10 & $4.9 \pm 1.9 \S$ & $10.4 \pm 1.9$ & $14.1 \pm 2.2$ & $9.3 \pm 1.6$ \\
\hline 5 & 3 & $5.9 \pm 1.2 \S$ & $12.1 \pm 1.6 \S$ & $15.2 \pm 1.5 \S$ & $9.3 \pm 3.5 \S$ \\
\hline \multicolumn{6}{|l|}{ Betamethasone } \\
\hline $1.0 \mathrm{mg} /$ every other day $\dagger$ & 5 & $1.2 \pm 0.6$ & $2.6 \pm 0.7$ & $4.7 \pm 1.1$ & $3.7 \pm 1.4$ \\
\hline
\end{tabular}

Values are expressed as the mean $\pm \mathrm{SD}$.

* The increment from the basal value to the maximum response either $30 \mathrm{~min}$ or $60 \mathrm{~min}$ after ACTH stimulation.

$\S$ No significant difference $(p>0.05)$ vs. untreated patients.

$\dagger$ The data at smaller doses generally indicate the results after long-term treatment, because the steroid doses were gradually tapered.

stronger and to continue longer than 24 hrs, even when such a small dose as 1.0 $\mathrm{mg}$ is given.

The chronic effect of the two steroids was examined with the rapid. ACTH test in this study. Even though this test was developed as a screening test for assessing the adrenocortical function by Wood et al. (1965), the results have been evaluated to reflect well the general status of the HPA function in glucocorticoid-treated patients (Kehlet and Binder, 1973). It is therefore felt that the present data represent the general status of the HPA function in patients receiving either prednisolone or betamethasone.

The present results indicate that the long-term administration of $10 \mathrm{mg}$ or more of prednisolone in daily divided doses suppresses the HPA function but a single administration of $10 \mathrm{mg}$ in the morning can reduce the HPA suppression. This result is consistent with the report of Myles et al. (1971) who found depressed 10:00 hr plasma cortisol levels in patients treated with prednisolone twice daily but found nearly normal cortisol levels in the same patients with a single daily administration. In the present study, the adrenocortical responsiveness was evaluated only on the basis of presently administered steroid doses without considering the duration of the therapy or the total amount of steroids. Therefore, even those who received only $5 \mathrm{mg}$ of prednisolone showed improved but still subnormal responses, because they had been treated with larger doses for a long time.

On the contrary, a long-term administration of betamethasone, even in a single dose of $0.5 \mathrm{mg}$ in the morning, was found to suppress the HPA function completely.

The alternate-day glucocorticoid therapy with a single dose in the morning of every second day was first proposed by Harter et al. (1963), and many authors have found. that such a regimen diminishes side effects of glucocorticoids and produces little or no suppression on the HPA function (Soyka, and Saxena, 1965 ; Fleisher and Pellecchia, 1965; Ackerman and Nolan, 1968; MacGregor et al., 1969; Easton et al., 1971). The present study based on the plasma cortisol responsiveness to ACTH also clearly indicates that the HPA function can be 
kept nearly normal during the alternate-day therapy with such a large dose as $60 \mathrm{mg}$ prednisolone. The reason why the HPA function does not differ so much between larger doses group and smaller doses group may be due to the difference in duration of the therapy, because the dose of prednisolone has gradually been tapered and rapid ACTH tests have been undertaken repeatedly in the same patients at different doses.

In contrast with the prednisolone therapy, the adrenocortical responsiveness was completey suppressed by the alternate-day therapy with betamethasone in even such a small dose as $1.0 \mathrm{mg}$. This result is consistent with earlier reports which showed that the HPA function is impaired if the alternate-day therapy is performed with long-acting steroids (Harter, 1966; Rabhan, 1968; Easton et al., 1971). The results of the present study indicate that the suppressibility of the HPA axis with so-called equivalent dosages of glucocorticoids with comparable anti-inflammatory activity is different and that the suppressive effect of long-term glucocorticoid therapy on the HPA function may be almost parallel to the acute suppressive effect on the circadian rhythm of plasma ACTH or cortisol.

\section{Acknowledgement}

The present work was partly supported by Grant No. 437008 from the Ministry of Education, Science and Culture, Japan.

\section{References}

Ackerman, G. L. and C. M. Nolan (1968). N. Engl. J. Med. 278, 405.

Axelrod, L. (1976). Medicine 55, 39.

Ballard, P. L., J. P. Carter, B. S. Graham and J. D. Baxter (1975). J. Clin. Endocrinol. Metab. 41, 290.

Besser, G. M., D. R. Cullen, M. J. Irvine, J. G. Ratcliff and J. Landon (1971). Br. Med. J. 1, 374.

Berson, S. A. and R. S. Yalow (1968). J. Clin. Invest. 47, 2725.

Boland, E. W. (1961). Am. J. Med. 31, 581.

Easton, J. G., R. J. Busser and E. M. Heimlich (1971). J. Allerg. Clin. Immunol. 48, 355.

Fleisher, D. S. and P. Pellecchia (1967). J. Pediat. $70,54$.

Grant, S. D., P. H. Forsham and V. C. DiRaimond (1965). N. Engl. J. Med. 273, 1115.

Harter, J. G., W. J. Reddy and G. W. Thorn (1963). ibid. 269, 591.

Harter, J. G. (1966). N. Y. State J. Med. 66, 827.

Hender, L. P. (1967). J. Endocrinol. 37, 57.

Kehlet, H. and C. Binder (1973). Br. Med. J. 1, 147.

MacGregor, R. R., J. N. Sheagren, M. B. Lipsett and S. M. Wolff (1969). N. Engl. J. Med. 280, 1427.

Meikle, A. W. and F. H. Tyler (1977). Am. J. Med. $63,200$.

Melby, J. C. (1974). Ann. Intern. Med. 81, 505.

Murphy, B. E. P. (1967). J. Clin. Endocrinol. Metab. 27, 973.

Murphy, B. E. P. (1969). Recent Progr. Horm. Res. 25, 563.

Myles, A. B., P. A. Bacon and J. R. Daly (1971). Ann. Rheum. Dis. 30, 149.

Nichols, T., C. A. Nugent and F. H. Tyler (1965). J. Clin. Endocrinol. Metab. 25, 343.

Peterson, R. E. (1959). Ann. N.Y. Acad. Sci. 82, 846. Rabhan, N. B. (1968). Ann. Intern. Med. 69, 1141.

Roberts, S. Clinical Uses of Adrenal Steroids (edited by J. Brown and C. M. Pearson). McGraw-Hill Book Co., N. Y. p. 333 (1962).

Silber, R. H. (1959). Ann. N. Y. Acad. Sci. 82, 821. Soyka, L. F. and K. M. Saxena (1965). J. Am. Med. Assoc. 192, 225.

Thorn, G. W. and D. P. Lauler (1972). Am. J. Med. $53,673$.

Tolksdorf, S. (1959). Ann. N.Y. Acad. Sci. 82, 829.

Wood, J. B., A. W. Frankland, V. H. T. James and J. Landon (1965). Lancet 1, 243. 